\title{
Lung volume distribution in prolonged mechanical ventilation patients from assist control mode to spontaneous trial mode of automatic tubing compensation in electrical impedance tomography
}

\author{
MY Chang ${ }^{1,2^{*}}$, HT Chang ${ }^{1,3}$ \\ From ESICM LIVES 2015 \\ Berlin, Germany. 3-7 October 2015
}

\section{Introduction}

Electrical impedance tomography (EIT) is a non-invasive and portable lung imaging technique for dynamic evaluation of lung volume distribution. Previous studies had proved the EIT can provide information on regional distribution of ventilation and changes in end-expiratory lung volume $(\triangle \mathrm{EELV})$. The effect of EIT application in ventilation distribution of prolonged mechanical ventilation (PMV) patients underwent weaning program is unknown.

\section{Objectives}

As an evidence-based strategy to predict successful weaning from assisted ventilation, automatic tube compensation (ATC) was developed to overcome the imposed work of breathing and airway resistance of endotracheal tube. The aim of the present study was to compare the spatial and temporal differences of ventilation distribution between control ventilation mode and $100 \%$ ATC in (PMV) patients.

\section{Methods}

PMV patients were ventilated under volume assist-control (AC) mode and subsequently under $100 \%$ ATC weaning. Spatial and temporal ventilation distributions were monitored with EIT. EIT data under AC mode 5 minutes before the switch to ATC and 50 minutes after switch were analyzed. We compared the data of end-expiratory lung impedance change $(\triangle E E L I)$, ventilation distribution in regions of interest (ROIs), ratio of tidal variation, the global inhomogeneity (GI) index, the center of ventilation

Far Eastern Memorial Hospital, Division of Pulmonary Medicine, Taipei City, Taiwan, Province of China

Full list of author information is available at the end of the article
$(\mathrm{CoV})$ index, regional ventilation delay (RVD) index of the lung regions in AC group and ATC group of the RCC population.

\section{Results}

A total of 16 PMV patients ( $M V>21$ days) in respiratory care center (RCC)were includedTidal variations during ATC100\% were significantly smaller than that during AC $(p<0.001)$. Regional ventilation distributions moved significantly towards dorsal regions during ATC100\% (EIT-based index center of ventilation, AC vs. ATC: $46.2 \pm 5.8$ vs. $51.7 \pm 6.5, p<0.001)$. Reginal ventilation delays were significantly reduced at ATC (50.2 \pm 10.3 vs. $39.3 \pm 6.9$ in dorsal regions, $p<0.001$ ).

\section{Conclusions}

We found significant difference in $\triangle E E L I$, ROIs, RVDI, GI index, and $\mathrm{CoV}$ in $100 \% \mathrm{ATC}$ trial as compared with AC mode. In conclusion, with EIT monitoring, we found ATC effectively stimulating the dorsal phrenic nerve to improve respiratory muscle weakness in PMV patients.

\section{Grant Acknowledgment}

This work was financially supported by project Far Eastern Memorial Hospital (FEMH-2015-C-069). The authors would like to thank Zhanqi Zhao for his continuous, enthusiastic, and smart support for this article.

\footnotetext{
Authors' details

${ }^{1}$ Far Eastern Memorial Hospital, Division of Pulmonary Medicine, Taipei City, Taiwan, Province of China. ${ }^{2}$ Institute of Medical Engineering and Materials Science, National Yang-Ming University, Taipei, Taiwan, Province of China. ${ }^{3}$ Far Eastern Memorial Hospital, Critical Care Medicine, New Taipei City, Taiwan, Province of China.
} 


\section{References}

1. Christian Putensen, et al: cal impedance tomography guided ventilation therapy. Anesthesiology 2007, 344-350.

2. Boles JM, et al: Weaning from mechanical ventilation. ERJ 2007, 29:1033-1056.

3. Zhao Z, et al: Evaluation of an electrical impedance tomography-based Global Inhomogeneity Index for pulmonary ventilation distribution. Intensive Care Med 2009, 35(11):1900-6, Nov.

4. Muders T, et al: Impedance tomography as a new monitoring technique. Curr Opin Crit Care 2010, 16:269-75.

doi:10.1186/2197-425X-3-S1-A666

Cite this article as: Chang and Chang: Lung volume distribution in prolonged mechanical ventilation patients from assist control mode to spontaneous trial mode of automatic tubing compensation in electrical impedance tomography. Intensive Care Medicine Experimental 2015

3(Suppl 1):A666.

\section{Submit your manuscript to a SpringerOpen ${ }^{\mathcal{O}}$ journal and benefit from:}

- Convenient online submission

- Rigorous peer review

- Immediate publication on acceptance

- Open access: articles freely available online

- High visibility within the field

- Retaining the copyright to your article 